\title{
Encefalite por varicella zoster em paciente com HIV assistido em hospital de referência no estado do Ceará
}

\author{
Encephalitis by varicella zoster in a patient with HIV assistant at the reference hospital in \\ the state of Ceará
}

\section{Encefalitis por varicella zoster en un paciente con VIH asistido en un hospital de referencia en el estado de Ceará}

Ramiro Moreira Tavares ${ }^{1 *}$, Christianne Fernandes Valente Takeda ${ }^{1}$, Severino Ferreira Alexandre ${ }^{1}$, Lívia de Andrade Gomes Feitosa ${ }^{1}$, Ravel Moreira Tavares².

\section{RESUMO}

Objetivo: Relatar etiologia rara de neuroinfecção em paciente com síndrome da imunodeficiência adquirida no Estado do Ceará. Detalhamentos de Caso: A encefalite por Varicella zoster (VZV) é uma desordem rara na população geral, geralmente se associa a condições que gerem queda de imunidade (quimioterapia, radioterapia, AIDS e outras doenças crônicas). Por não ser condição de notificação espontânea não há dados sobre sua ocorrência no Brasil, e sobretudo no Nordeste do país.Descrevemos um caso de paciente com achados clínicos e laboratoriais no contexto neuroinfecção com déficit motor, associado ao HIV, apresentando-se como provável quadro relacionado a doenças oportunistas, no entanto sem achados de imagem compatíveis, sendo identificado Varicella zoster no liquor, mesmo sem a ocorrência de quadro dermatológico prévio. Considerações finais: Em pacientes com HIV, a encefalite por VZV merece ser lembrada como diagnóstico diferencial em todos os quadros de neuroinfecção. O uso de técnicas de biologia molecular no diagnóstico mostrou-se promissor, reduzindo tempo de internação, otimizando terapêutica e reduzindo complicações e mortes.

Palavras-chave: HIV, Encefalite por varicella zoster, Encefalite, Coinfecção, Infecções por HIV.

\begin{abstract}
Objective: To report a rare etiology of neuroinfection in a patient with acquired immunodeficiency syndrome in the State of Ceará. Case Details: Varicella zoster encephalitis (VZV) is a rare disorder in the general population, usually associated with conditions that cause a drop in immunity (chemotherapy, radiotherapy, AIDS and other chronic diseases). Since it is not a condition for spontaneous notification, there are no data on its occurrence in Brazil, and especially in the Northeast of the country. related to opportunistic diseases, however without compatible imaging findings, Varicella zoster being identified in the CSF, even without a previous dermatological condition. Conclusion: In patients with HIV, VZV encephalitis deserves to be remembered as a differential diagnosis in all cases of neuroinfection. The use of molecular biology techniques in the diagnosis proved to be promising, reducing hospital stay, optimizing therapy and reducing complications and deaths.
\end{abstract}

Keywords: HIV, Varicella zoster encephalitis, Encephalitis, Coinfection, HIV infections.

\footnotetext{
${ }^{1}$ Hospital São José de Doenças Infecciosas (HSJ), Fortaleza - Ceará. *E-mail: ramiromtavares@gmail.com

${ }^{2}$ Faculdade de Medicina de Juazeiro/Estácio (FMJ/Estácio), Juazeiro do Norte - Ceará.
}

SUBMETIDO EM: 4/2020

ACEITO EM: 4/2020

PUBLICADO EM: 4/2020 


\section{RESUMEN}

Objetivo: Informar una etiología rara de neuroinfección en un paciente con síndrome de inmunodeficiencia adquirida en el estado de Ceará. Detalles del caso: La encefalitis por varicela zoster (VZV) es un trastorno poco frecuente en la población general, generalmente asociado con afecciones que causan una disminución de la inmunidad (quimioterapia, radioterapia, SIDA y otras enfermedades crónicas). Como no es una condición para la notificación espontánea, no hay datos sobre su ocurrencia en Brasil, y especialmente en el noreste del país. Describimos un caso de un paciente con hallazgos clínicos y de laboratorio en el contexto de neuroinfección con déficit motor, asociado con el $\mathrm{VIH}$, que se presenta como una condición probable. relacionado con enfermedades oportunistas, sin embargo, sin hallazgos de imágenes compatibles, Varicella zoster se identifica en el LCR, incluso sin la aparición de una condición dermatológica previa. Conclusión: En pacientes con VIH, la encefalitis por VZV merece ser recordada como un diagnóstico diferencial en todos los casos de neuroinfección. El uso de técnicas de biología molecular en el diagnóstico resultó prometedor, reduciendo la estancia hospitalaria, optimizando la terapia y reduciendo las complicaciones y muertes.

Palabras clave: VIH, Encefalitis por varicela zoster, Encefalitis, Coinfección, Infecciones por VIH.

\section{INTRODUÇÃO}

O Varicella zoster (VZV) é um DNA-vírus patológico em humanos (BRASIL, 2017) e além de quadros cutâneos em infecção primária pode causar neuroinfecção, por reativação, manifestando-se principalmente como ataxia cerebelar aguda e encefalite (TAVARES W e MARINHO LAC, 2015). A encefalite pelo vírus é condição rara na população, apesar de ocorrer em imunocompetentes, esta apresentação geralmente se associa a imunodeficiência, como em pacientes em quimioterapia, radioterapia e na Síndrome da Imunodeficiência Adquirida (AIDS), não sendo necessariamente precedida de lesões cutâneas (TAVARES W e MARINHO LAC, 2015; KOSKINIEMI M, et al., 2002).

Após uma infecção primária o VZV permanece latente nos gânglios nervosos, sendo capaz de reativa-se e se replicar durante estados de imunidade reduzida, particularmente a imunidade celular, migrando dos gânglios ao longo dos axônios neuronais para a pele, resultando em herpes zoster, e em raras situações a reativação pode fazer dano generalizado levando a encefalite (AMLIE-LEFOND C, JUBELT B, 2009; BANGEN KJ, et al., 2010).

Estima-se que a encefalite por VZV ocorra entre 0,1 a $0,2 \%$ dos pacientes que desenvolveram varicela (COURA JR, 2015). Em análise de bancos de dados dos Estados Unidos observa-se 27.262.603 pessoas com casos de herpes zoster entre 1993 a 2016, sendo identificados em 62\% no sexo feminino (HARPAZ R, LEUNG JW, 2019). Não há dados precisos sobre a ocorrência anual de encefalite por zoster (BANGEN KJ, et al., 2010), alguns estudos apontam para predominancia de encefalite no sexo masculino (CORTI M, et al., 2015). Estima-se mortalidade por encefalite por Varicella zoster entre 9-20\% (GRAHN A, STUDAHL M, 2015).

A sintomatologia neurológica está associada a dano de pequenas e grandes artérias cerebrais, causando uma vasculopatia que resulta em infartos de tecido cerebral uni ou multifocal, podendo ser observado em crianças e adultos (AMLIE-LEFOND C, JUBELT B, 2009; KOSKINIEMI M, et al., 2002; BHAYANI N, et al., 2008). Em pacientes imunossuprimidos o dano vascular pode predispor a lesões desmielinizantes (WIĘDŁOCHA M, et al., 2015).

Este trabalho tem como objetivo descrever um caso de neuroinfecção por reativação de Varicella zoster, em paciente portador do vírus da Imunodeficiência adquirida (HIV), com SIDA, sem a ocorrência de quadro dermatológico prévio.

\section{RELATO DE CASO}

Descrevemos um caso de um paciente do sexo masculino, 26 anos, pardo, pessoa vivendo com HIV (PVHIV) desde 2016, iniciou tratamento para tuberculose pulmonar (TB) em janeiro de 2019, com esquema 
básico, com Rifampicina $(R)$, Isoniazida $(H)$, Pirazinamida $(Z)$ e Etambutol $(E)$ por 2 meses, seguindo com $\mathrm{R}+\mathrm{H}$ em atenção básica, e terapia antirretroviral (TARV) em abril de 2019, com quantificação inicial de linfócitos TCD4 (auxiliaries) de 31 células/ $\mu \mathrm{l}$, carga viral inicial >5 logs, 443159 cópias/ $\mu \mathrm{l}$.

Em 15/04/19 deu entrada na emergência por quadro de evolução de uma semana com cefaléia hemicraniana a direita, náuseas, vômitos, escotomas visuais, turvação visual, hemiparesia à esquerda, zumbido em ouvido direito, diarreia aquosa e perda ponderal (não quantificada). Foi internado e submetido a tomografia computadorizada de crânio (TC) sem contraste que mostrou imagem com hipoatenuação mal definida em região capsulo-talâmica direita de aspecto inespecífico, sem efeitos de massa e sem desvio de linha média (Figura 1). O estudo do líquido cefaloraquidiano (LCR) mostrou discreta pleocitose (14 células) predominando linfomononucleares (86\% de linfócitos), com discreta hiperproteinorraquia $(53,52 \mathrm{mg} / \mathrm{dl}) \mathrm{e}$ VDRL 1:16 (com VDRL sérico 1:1024). Paciente foi admitido e foi iniciado tratamento para neurotoxoplasmose (NTX), empiricamente, com sulfadiazina, pirimetamina e ácido folínico, bem como penicilina cristalina venosa para neurossífilis.

Figura 1 - Tomografia de crânio sem contraste evidencia hipoatenuação mal definida em região capsulo-talâmica direita de aspecto inespecífico, sem efeitos de massa nem desvio de linha média, não evidenciando achado específico para definição diagnóstica.

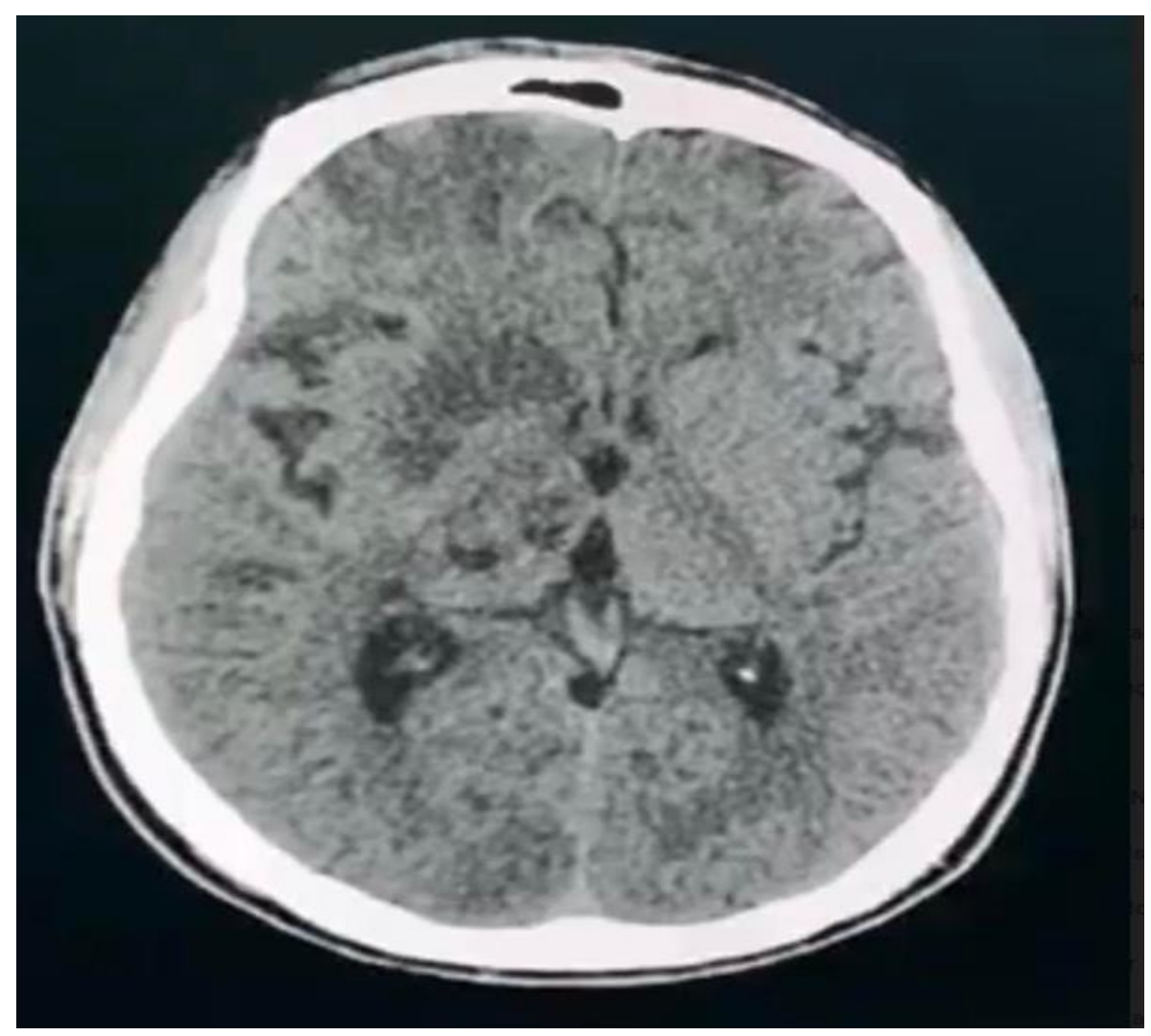

Fonte: Tavares RM, et al., 2020.

A TC com contraste, realizada em 06/05/2019 (Figura 2), revelou imagens ovaladas hipodensas em núcleos capsulares e tálamo a direita, sem realce pós contraste, sendo então optado pela manutenção do esquema para neurotoxoplasmose (com sulfadiazina, pirimetamina e ácido folínico) e TB (R e H). O paciente evoluiu com melhora dos sintomas incluindo o déficit motor, com necessidade reduzida de auxílio para as atividades de vida diária. Ele recebeu alta hospitalar em 10/05/2019 para continuação de terapias em domicílio e seguimento ambulatorial. 
Figura 2 - Imagens ovaladas hipodensas em núcleos capsulares e tálamo a direita, sem realce pós contraste.

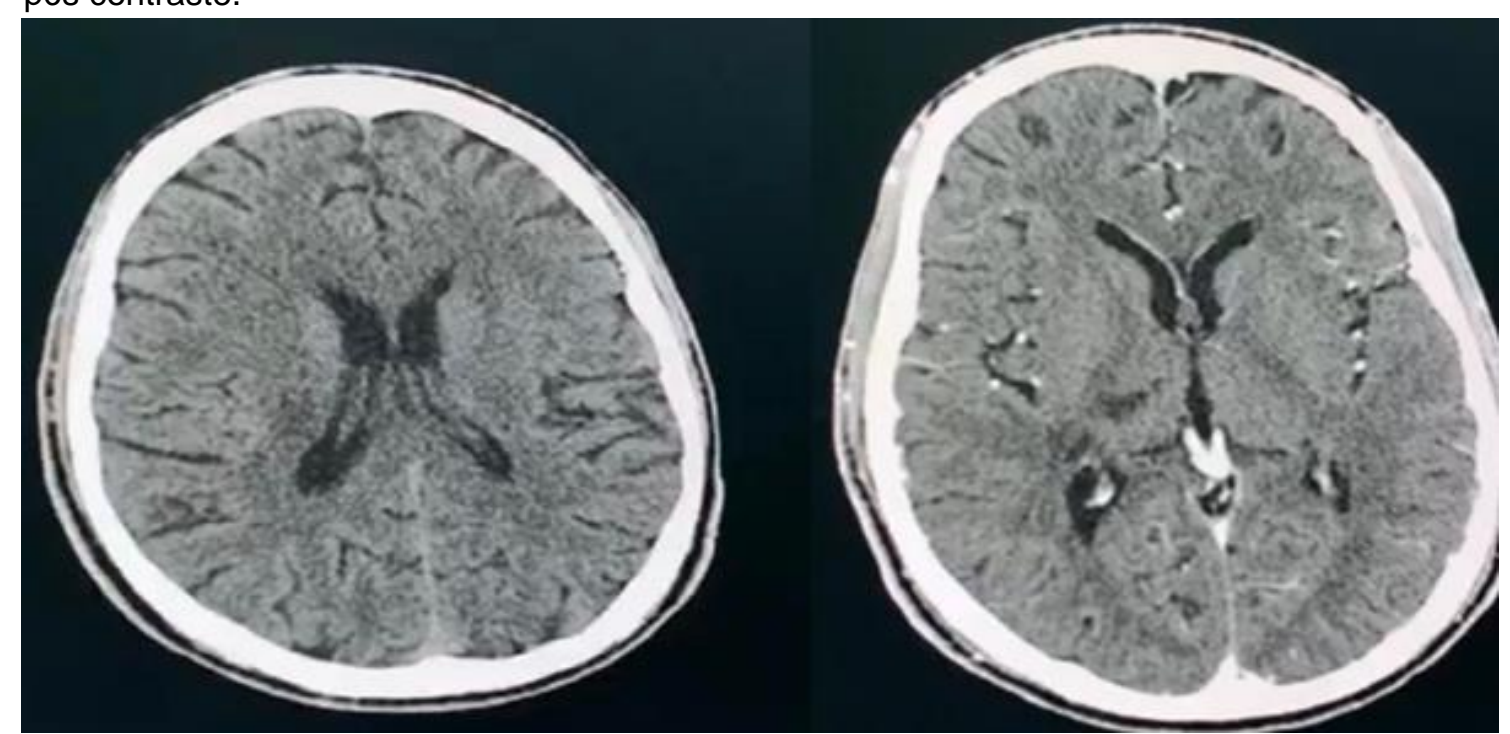

Fonte: Tavares RM, et al., 2020.

Após duas semanas de sua alta, paciente retornou à emergência em 24/05/2019 com cefaleia, disfonia, piora da hemiparesia a esquerda, zumbido e sonolência, sendo reiniciado esquema para neurotoxoplasmose. Fez nova TC sem contraste que demonstrou áreas de hipoatenuação em região nucleocapsular e centro semioval à direita e na região parietal, sem determinação de efeito de massa, ou desvio de linha média (Figura 3).

Figura 3 - áreas de hipoatenuação em região nucleocapsular e centro semioval à direita e na região parietal, sem determinação de efeito de massa, ou desvio de linha média.

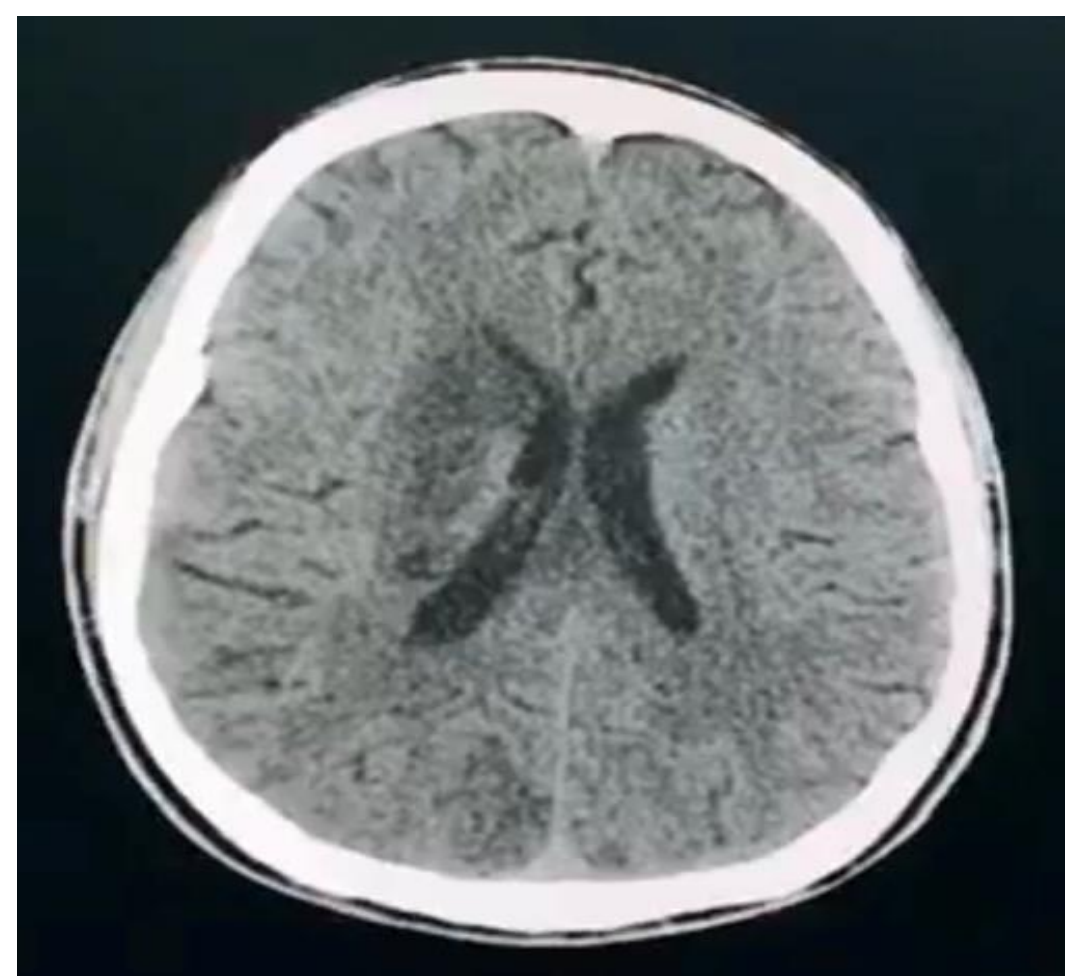

Fonte: Tavares RM, et al., 2020. 
Diante da imagem optou-se por realizar novo estudo do LCR em 29/05, que identificou uma amostra de líquor límpida, com discreta pleocitose (12 células) linfocítica (72\% de linfócitos, 22\% de monócitos e 6\% de neutrófilos), discreta hiperproteinorraquia $(77 \mathrm{mg} / \mathrm{dl}$ ), e glicorraquia normal ( $<2 / 3$ glicemia sérica). Apesar de culturas de LCR negativas e de se observar uma queda da titulação do VDRL no líquor 1:8 (VDRL sérico de 1:32), o líquido cefalorraquidiano foi submetido a análise com técnica de biologia molecular de Reação de Cadeia Polimerase ou PCR (polymerase chain reaction) Multiplex que identificou vírus Varicella zoster. Após nova anamnese, paciente relatou ter antecedente de quadro cutâneo de varicela na infância, aos 4 anos de idade.

Assim, diante do achado de PCR no LCR foi instituído esquema terapêutico com aciclovir endovenoso na dose de $10 \mathrm{mg} / \mathrm{kg} / \mathrm{dose}$, (625mg 8/8h) por 21 dias. Paciente apresentou melhora do grau de funcionalidade (i.e. verbalizava, aceitava dieta oferecida, deambulava com auxílio), tendo ao término de tratamento parenteral recebido alta para seguimento ambulatorial.

Durante o internamento por encefalite herpética foi concluído o tratamento para tuberculose pulmonar (tratou por seis meses). Quanto a neurotoxoplasmose, ao final do tratamento o paciente iniciou esquema de profilaxia secundária com sulfadiazina, pirimetamina e ácido folínico, além da manunetenção da terapia antirretroviral.

\section{DISCUSSÃO}

Neste trabalho, apresentamos um caso de encefalite por VZV em paciente com AIDS. O Varicella zoster é membro da família Herpesviridae que causa varicela em primo-infecção, podendo reativar-se com herpes zoster e complicações neurológicas (CORTI M, et al., 2015).

Assim como neste relato, a encefalite por este vírus geralmente afeta mais comumente indivíduos imunocomprometidos, além de pessoas de meia-idade e idosos, independente de comorbidades, sendo a ausência de doenças associadas condição considerada rara (KOSKINIEMI M, et al., 2002, WIĘDŁOCHA M, et al., 2015).

Na primeira internação, o paciente foi tratado para NTX e neurossífilis, ocorrendo melhora dos sintomas após início do tratamento. A toxoplasmose é a causa mais comum de lesões expansivas cerebrais em PVHIV, acredita-se que a neurotoxoplasmose se desenvolva por reagudização de infecção latente, seu diagnóstico definitivo necessita de confirmação histopatológica (BRASIL, 2018; BASILIO-DE-OLIVEIRA CA, 2015). Pacientes com HIV com quadro neurológico e imagem sugestiva recomenda-se por trata-lo empiricamente como NTX, sendo o esquema terapêutico de escola a associação de sulfadiazina, pirimetamina e ácido folínico ou sulfametoxazol e trimetoprima por seis (6) semanas, em casos de intolerância as sulfas fazer substituição da mesma por clindamicina, em associação com pirimetamina e ácido folínico (BRASIL, 2018). Mesmo com a introdução deste esquema terapêutico não observamos resolução das queixas iniciais.

O envolvimento do sistema nervoso central (SNC) pela sífilis pode-se observar já nas fases iniciais da infecção, ocorrendo em $10-40 \%$ dos pacientes não tratados. A maioria dos pacientes é assintomática, a doença só é diagnosticada pela análise de líquor onde a presença de pleocitose por mononucleares é critério de baixa sensibilidade, esta alteração pode estar presente em outras condições como pelo vírus HIV e toxoplasmose, requerendo a análise e o achado de VDRL no LCR para fechar diagnóstico de neurossífilis (TAVARES W e MARINHO LAC, 2015; BRASIL, 2018), como evidenciado no caso. A titulação elevada de teste não treponêmico no líquor levou o paciente a receber penicilina cristalina, que é a droga de escolha na neurossífilis (BRASIL, 2019), no entanto não levou a resolução do quadro.

Há registro na literatura da ocorrência de encefalite por VZV e outros agentes em coinfecção (BANGEN $\mathrm{KJ}$, et al., 2010), como neste evento. É importante considerarmos a presença de DNA do VZV no LCR concomitantemente com outros vírus ou simultaneamente com a ocorrência de complicações neurológicas do HIV, independente da ocorrência de lesões mucocutâneas do VZV (CORTI M, et al., 2015). Mesmo diante de achados de imagem ou identificação de outras etiologias não devemos deixar de considerar Varicella zoster como agente neuropatogênico, principalmente em indivíduos imunodeprimidos. 
O VZV atinge o sistema nervoso por transporte axonal retrógrado ou pela corrente sanguínea, uma vez reativado, o vírus mostra predileção por primeiro neurônio sensitivo (BASILIO-DE-OLIVEIRA CA, 2015; JI Y, et al., 2019), estima-se que o virus seja carreado até os neurônios pelas células $T$, que ao se ligarem aos neurônios iniciam a cadeia de neuropatogênese (GRAHN A, STUDAHL M, 2015). Neste caso observamos a ocorrência de hemiparesia a esquerda. Os mecanismos patogênicos da reativação do vírus no SNC incluem infecção direta neuronal e glial e lesões imunomediadas, incluindo vasculite e desmielinização (CORTI M, et al., 2015).

A vasculopatia de pequenos vasos é característica de pacientes com imunossupressão, podendo a arterite granulomatosa de grandes vasos, a ventriculite e a periventriculite surgirem como complicações neurológicas do Varicella zoster (WIĘDŁOCHA M, et al., 2015), diferentes manifestações do SNC também podem ocorrer em conjunto, uma vez que vários vasos podem ser afetados (GRAHN A, STUDAHL M, 2015) . A prevalência de vasculopatia por VZV após sua reativação é desconhecida na poulação geral, no entanto há relatos na literatura de aumento da incidência de eventos vasculares cerebrais no primeiro ano após neuroinfecção (GRAHN A, STUDAHL M, 2015).

Os achados de neuroimagem nas infecções por VZV em SNC geralmente estão ausentes, mas a utilização de métodos de tomografia computadorizada (TC) e ressonância nuclear magnética (RNM) podem revelar anormalidades (GRAHN A, STUDAHL M, 2015). O vírus pode gerar achados de imagem que abrem outras hipóteses diagnósticas, como NTX, assim retardando o tratamento para VZV. As desordens no SNC incluem encefalomielite (relatamos um caso de encefalite), herpes-zoster oftálmico, encefalite trigeminal e vasculopatia cerebral (BASILIO-DE-OLIVEIRA CA, 2015)

Neste relato o diagnóstico de neuroinfecção por VZV foi feito através de método de biologia molecular, o PCR Multiplex. A amplificação do DNA do VZV no líquor pela PCR é o método padrão ouro no diagnóstico de distúrbios neurológicos associados ao herpesvírus (CORTI M, et al., 2015). A ocorrência de anticorpos intratecais é menos específica que a busca pelo DNA do vírus (KOSKINIEMI M, et al., 2002). Com a difusão de métodos de PCR tem-se observado a relação custo-benefício mais viável nos serviços de saúde.

O paciente apresentou melhora com uso do aciclovir endovenoso, que é a droga de escolha para o tratamento desta patologia. O aciclovir é um derivado análogo da guanosina, sendo inibidor da DNApolimerase após a sua fosforilação pela timidina-quinase viral, tendo sua via de administração para infecções em SNC intravenosa, na dose de 10mg/kg de 8/8hs (TAVARES W e MARINHO LAC, 2015), são raros os eventos de resistência viral, sendo mais observados em pacientes imunodeprimidos, geralmente associada a mutações na região de codificação da timidina quinase viral. (GRAHN A, STUDAHL M, 2015).

Outros antivirais como o fanciclovir e o ganciclovir podem ser utilizados como alternativas (VENKATASUBRAMANIAN C, et al, 2019; WHO, 2019), no entanto assim como o aciclovir dependem da enzima timidina-quinase viral. O foscarnet, ao contrário do ganciclovir, fanciclovir e aciclovir não dependem da enzima viral e é alternativa em casos de falha, toxicidade limitante da dose ou suspeita de resistência viral ao aciclovir (QUAN SC QS, SKONDRA D, 2019), a droga é inibidora da DNA-polimerase, por ligação ao pirofosfato da enzima bloqueando a clivagem da fração pirofosfato dos trifosfatos desoxinucleotídicos, interrompendo o alongamento da cadeia do DNA viral (PORTUGAL ME e RABONI SM, 2017), no entanto esta droga não é disponível no Brasil.

A infecção pelo VZV em SNC tem prognóstico favorável em crianças (apesar de poucos estudos de acompanhamento estarem disponíveis), em adultos, o prognóstico é bom em termos gerais, com relatos de doenças mais graves em imunocoprometidos. Estudos indicam sequelas neurológicas graves, incluindo sequelas cognitivas (GRAHN A, STUDAHL M, 2015).

Apesar de também ser presente em imunocompetentes, a neuroinfecção por VZV é comum em indivíduos com HIV, representando $2 \%$ dos casos de envolvimento neurológico pelo vírus (CORTI M, et al., 2015). A reativação do vírus em pacientes com AIDS geralmente está associada a meningoencefalite aguda e grave (CORTI M, et al., 2015), sendo a maioria dos casos observados em indivíduos com grande depleção de CD4 (NAGEL MA, et al., 2008). Neste paciente observamos que ele tinha história pregressa de infecção primária 
por VZV na infância (aos quatro anos de idade), bem como imunossupressão importante, dada a infecção não controlada pelo HIV.

Diante do exposto, concluí-se primeiramente que, em pacientes com HIV, a encefalite por VZV merece ser lembrada como diagnóstico diferencial em todos os quadros de neuroinfecção, mesmo sem lesões cutâneas prévias. Finalmente, sabendo que o diagnóstico etiológico precoce otimiza as medidas terapêuticas, diminui tempo de hospitalização, risco de complicações e mortes, além de otimizar de custos ao sistema de saúde, o uso de métodos de biologia molecular como PCR Multiplex utilizado neste caso mostra-se promissor.

\section{REFERÊNCIAS}

1. AMLIE-LEFOND C, JUBELT B. Neurologic manifestations of varicella zoster virus infections. Curr Neurol Neurosci Rep, 2009; 9(6): 430-4.

2. BANGEN KJ, et al. Dementia Following Herpes Zoster Encephalitis. The Clinical Neuropsychologist, 2010; 24(7): 1193-203.

3. BASÍLIO-DE-OLIVEIRA, CA, et al. ATLAIDS - Atlas de patologia da Síndrome da Imunodeficiência Adquirida (AIDS/HIV) - 2 $2^{\mathrm{a}}$ edição - São Paulo, Rio de Janeiro, Belo Horizonte. Editora Atheneu, 2015, p363-369.

4. BHAYANI N, RANADE P, CLARK NM, MCGUINN M. Varicella-Zoster Virus and Cerebral Aneurysm: Case Report and Review of the Literature. Clin Infect Dis, 2008; 47(1): e1-3.

5. BRASIL - MINISTÉRIO DA SAÚDE - GUIA DE VIGILÂNCIA EM SAÚDE, VOLUME ÚNICO. Coordenação geral de desenvolvimento da epidemiologia em serviços. Brasília: Ministério da Saúde do Brasil; 2017. p153.

6. BRASIL - Protocolo Clínico e Diretrizes Terapêuticas para Manejo da Infecção pelo HIV em Adultos. Departamento de Doenças de Condições Crônicas e Infecções Sexualmente Transmissíveis. Brasília: Ministério da Saúde do Brasil; 2018. (27) p241-255, (35) p295-298.

7. CORTI M, et al. Meningoencephalitis due to varicella zoster virus in aids patients. Report of eleven cases and review of the literature. Revista do Instituto de Medicina Tropical de São Paulo, $2015 ; 57(6): 505-8$.

8. COURA JR. Dinâmica das doenças infecciosas e parasitárias - $2^{\mathrm{a}}$ edição. Rio de Janeiro: Guanabara Koogan, 2015; (170) p1955-1961.

9. GRAHN A, STUDAHL M. Varicella-zoster virus infections of the central nervous system - Prognosis, diagnostics and treatment. Journal of Infection, 2015. Volume 71, Issue 3, Pages 281-293

10. HARPAZ R, LEUNG JW. The Epidemiology of Herpes Zoster in the United States During the Era of Varicella and Herpes Zoster Vaccines: Changing Patterns Among Older Adults. Clinical Infectious Diseases, 2019; 69(2): 341-344.

11. JI Y, et al. Ramsay Hunt syndrome with pontine lesion: A case report. Medicine, $2019 ; 98(5)$.

12. KOSKINIEMI M, et al. Acute central nervous system complications in varicella zoster virus infections. Journal of Clinical Virology, 2002; 25(3):293-301.

13. NAGEL MA, et al. The varicella zoster virus vasculopathies: clinical, CSF, imaging, and virologic features. Neurology, 2008;70(11): 853-60.

14. PORTUGAL ME, RABONI SM. Antiviral drug review: a guide to clinicians. Revista de patologia tropical, 2017; 46(1): 01-21.

15. QUAN SC QS, SKONDRA D. Case Report: Varicella-zoster Encephalitis with Acute Retinal Necrosis and Oculomotor Nerve Palsy. Optometry and vision science: American Academy of Optometry, 2019; 96(5):367-371.

16. TAVARES W, MARINHO LAC. Rotinas de diagnóstico e tratamento das doenças infecciosas e parasitárias. Edição: 4. São Paulo: Editora Atheneu; 2015. 1083p.

17. VENKATASUBRAMANIAN C, et al. Emergency Neurological Life Support: Fourth Edition, Updates in the Approach to Early Management of a Neurological Emergency. Neurocrit Care, 2019; (32):636-640.

18. WIĘDŁOCHA M, MARCINOWICZ P, STAŃCZYKIEWICZ B. Psychiatric aspects of herpes simplex encephalitis, tickborne encephalitis and herpes zoster encephalitis among immunocompetent patients. Adv Clin Exp Med, 2015;24(2):361-71.

19. WHO - WORLD HEALTH ORGANIZATION EUROPE. Management of opportunistic infections and general symptoms of hiv/aids - Clinical protocol for the WHO European Region. Copenhage: WHO; 2019. p.23. 